\title{
3D interpretation of helicopter-borne frequency-domain electromagnetic (HEM) data from Ramså Basin and adjacent areas at Andøya, Norway
}

\author{
Vikas Chand Baranwal ${ }^{*}$, Marco Brönner ${ }^{1}$, Jan-Steinar Rønning ${ }^{1,2}$, Harald Elvebakk ${ }^{1}$ and Einar Dalsegg ${ }^{1}$
}

\begin{abstract}
The Ramså Basin is situated on the strandflat on the northeastern side of Andøya between Ramså and Skarstein. It is the only known Mesozoic sedimentary basin onshore Norway and therefore represents an easily accessible analogue to study the setting and development of the offshore Mesozoic basins along the Norwegian continental shelf. Basement rocks (100-10,000 $\Omega \mathrm{m})$ and sedimentary rocks $(5-1000 \Omega \mathrm{m})$ have distinct ranges of the electrical resistivity. Resistivity of the subsurface can be investigated by electric and electromagnetic (EM) methods to delineate the extent of the sedimentary basin. This paper presents the interpretation of helicopter-borne frequency-domain electromagnetic (HEM) data and their correlation with data obtained from borehole logging and two-dimensional (2D) electrical resistivity tomography (ERT). Resistivity data obtained from these methods show a good agreement. Spatially constrained inversion (SCl) of HEM presents a three-dimensional (3D) subsurface resistivity image of a larger area in comparison to what could have been drawn from few ERT lines and borehole logging. HEM interpretation together with other ERT and borehole resistivity data indicates the extent of Ramså Basin beyond the presently mapped boundary. This extension is also supported by interpretation of earlier collected gravity, magnetic and seismic data. The Ramså sedimentary basin shows a wide range of electrical resistivity between ca. 10 and $600 \Omega \mathrm{m}$ at different depths. Two highly conductive areas are newly identified by HEM data interpretation. In one of these areas, outcropping graphite and sulfide minerals were found by field observations.
\end{abstract}

Keywords: Airborne EM, Ramså Basin, Frequency-domain helicopter-borne electromagnetic (HEM), Spatially constrained inversion (SCl), Mesozoic bedrock

\section{Introduction}

The Ramså Basin at Andøya, Northern Norway, is the only known Mesozoic basin onshore Norway. It is situated along the strandflat on the northeastern side of Andøya between Ramsa and Skarstein. The thickness of the sedimentary basin is reported to be more than $650 \mathrm{~m}$ (Dalland 1975). Deeply weathered materials are exposed at the surface (Brönner et al. 2012, 2017) and are also

\footnotetext{
*Correspondence: Vikas.Baranwal@ngu.no

${ }^{1}$ Geological Survey of Norway (NGU), Torgarden, Postbox 6315,

Trondheim 7491, Norway

Full list of author information is available at the end of the article
}

observed in the drill-cores in the Ramså Basin (Vogt 1905; Dalland 1975). The weathered bedrock is overlain by Mid-Jurassic to Cretaceous sedimentary rocks.

To better understand the geology of the region and extent of the Ramså Basin, a comprehensive multi-geophysics project was carried out between 2012 and 2016 comprising helicopter-borne frequency-domain electromagnetics (HEM), airborne gravity and magnetic, twodimensional (2D) electrical resistivity tomography (ERT), borehole logging and 2D seismic surveys. Data and results from the different surveys are described in Brönner et al. (2017). Direct current (DC) and electromagnetic 
(EM) methods map resistivity to identify different rock types, conductive minerals and weathered and fractured bedrock. In this paper, we present the modeling and integrated interpretation results of the electrical resistivity and electromagnetic data. Six 2D ERT profiles were collected in 2010 (Brönner et al. 2012). An airborne HEM survey in 2012 (Rodionov et al. 2012) followed ERT survey to map the basin boundary and to investigate the appearance of weathered and fractured basement. Later, four boreholes were drilled and logged in 2015 and 2016 (Elvebakk et al. 2016). Locations of these boreholes were chosen based on the initial interpretation of airborne geophysical data and seismic profiling.

Airborne EM (AEM) surveys using various types of EM transmitter and receiver coils are deployed either on fixed-wing aircraft or helicopter. AEM methods have been used successfully for various geological and hydrogeological investigations, e.g., river clay mapping (Asch et al. 2008), groundwater exploration (Ley-Cooper et al. 2008; Siemon et al. 2011), tunnel construction (Okazaki et al. 2011), depth-to-bedrock mapping (Christensen et al. 2015), three-dimensional (3D) geological modeling (Høyer et al. 2015) and mineral exploration (Roach et al. 2014). The measurements are performed by different AEM systems using either time or frequency domain. A review of various AEM systems can be found in Siemon et al. (2009), Legault (2015) and Auken et al. (2017).

Subsurface resistivity images are obtained from AEM data using homogeneous half-space, one-dimensional (1D) and 3D inversions. 2D modeling of AEM data is not very common, though some codes can be found in the literature ( $\mathrm{Li}$ et al. 2016). Recently, full 3D inversion codes were developed to invert AEM data (Cox et al. 2012; Liu and Yin 2016; Scheunert et al. 2016; Liu et al. 2018). Quasi-3D inversion or spatially constrained inversion (SCI) using 1D forward modeling is extensively used to invert AEM data for groundwater and mineral exploration applications (Anschütz et al. 2014; Høyer et al. 2015). Quasi-3D inversion may produce results similar to full 3D inversion in 2D environments when sufficiently long horizontal layers of a few hundred meters are present in the area justifying the use of 1D forward modeling in the inversion (Viezzoli et al. 2010). However, SCI with 1D forward modeling fails to recover the correct resistivity in the vicinity of the boundaries of the horizontal layers (Guillemoteau et al. 2011).

Inversion results from HEM data and their correlation with ERT and borehole logging data are presented in this paper. A quasi-3D inversion of HEM data depicts a 3D subsurface resistivity image of the area around the Ramså Basin. The inverted resistivity obtained from HEM data inversion was subsequently compared with borehole resistivity logs from the four recently core drilled holes and 2D ERT profiles to cross-check its validity. The inversion result is correlated to bedrock, possible bedrock alteration, boundary between sedimentary rocks and basement since these different rock units show distinct resistivity ranges.

\section{Geology of the area}

The existing bedrock map of Andøya (Henningsen and Tveten 1998) is shown in Fig. 1. The primary basement rocks in the area are mainly granodiorite, granite and gabbro. The sedimentary rocks in the Ramså Basin consist of sandstone with different variations of clay and shales from Mid-Jurassic to early Cretaceous age (Dalland 1975; Midbøe 2011). Few bands of quartzite are also observed as part of supra-crustal metasedimentary rocks in the Skogsvoll group, south of the Ramså Basin.

Most of Andøya is covered by Quaternary marine clay deposits, moraine and bog. The cover varies from a few meters to tens of meters at different locations. The original onshore boundary of the Ramså sedimentary basin is derived from Henningsen and Tveten (1998) which was refined on the basis of few shallow drill holes (Friis 1903; Vogt 1905) and is shown by the green line in Fig. 1.

\section{Geophysical surveys HEM survey \\ Data acquisition in HEM survey}

The HEM data presented here were collected at five different frequencies using a Hummingbird system (Geotech 1997). Three frequencies (34,133, 6606 and $880 \mathrm{~Hz})$ were set in horizontal coplanar settings and two frequencies (7001 and $980 \mathrm{~Hz}$ ) in vertical coaxial settings. A 7.5-m-long bird containing transmitter and receiver coils of all five frequencies was fastened with a 30-m-long wire below the helicopter and flown in E-W direction at $200 \mathrm{~m}$ line spacing. Terrain clearance was measured with a radar altimeter fixed to the helicopter. Average terrain clearance of the bird was ca. $56 \mathrm{~m}$. HEM data were recorded at every $0.1 \mathrm{~s}$ to give a ca. $3 \mathrm{~m}$ data interval. The flight lines of HEM survey are shown by thin black lines in Fig. 1.

A quasi-3D inversion (or SCI) was performed for the HEM data within the red polygon (Fig. 1) that covers the Ramså sedimentary basin area. Exposed basement region, west of the Ramså Basin (west of the upper part of L-shaped region), produced a low-magnitude HEM response, therefore it was not interesting to investigate. The selection was extended further south to cover a region with high-magnitude HEM response. The position of six ERT profiles collected in 2010 is shown as blue lines (Fig. 1). The four boreholes used for resistivity and other geophysical logging in 2015 and 2016 are 


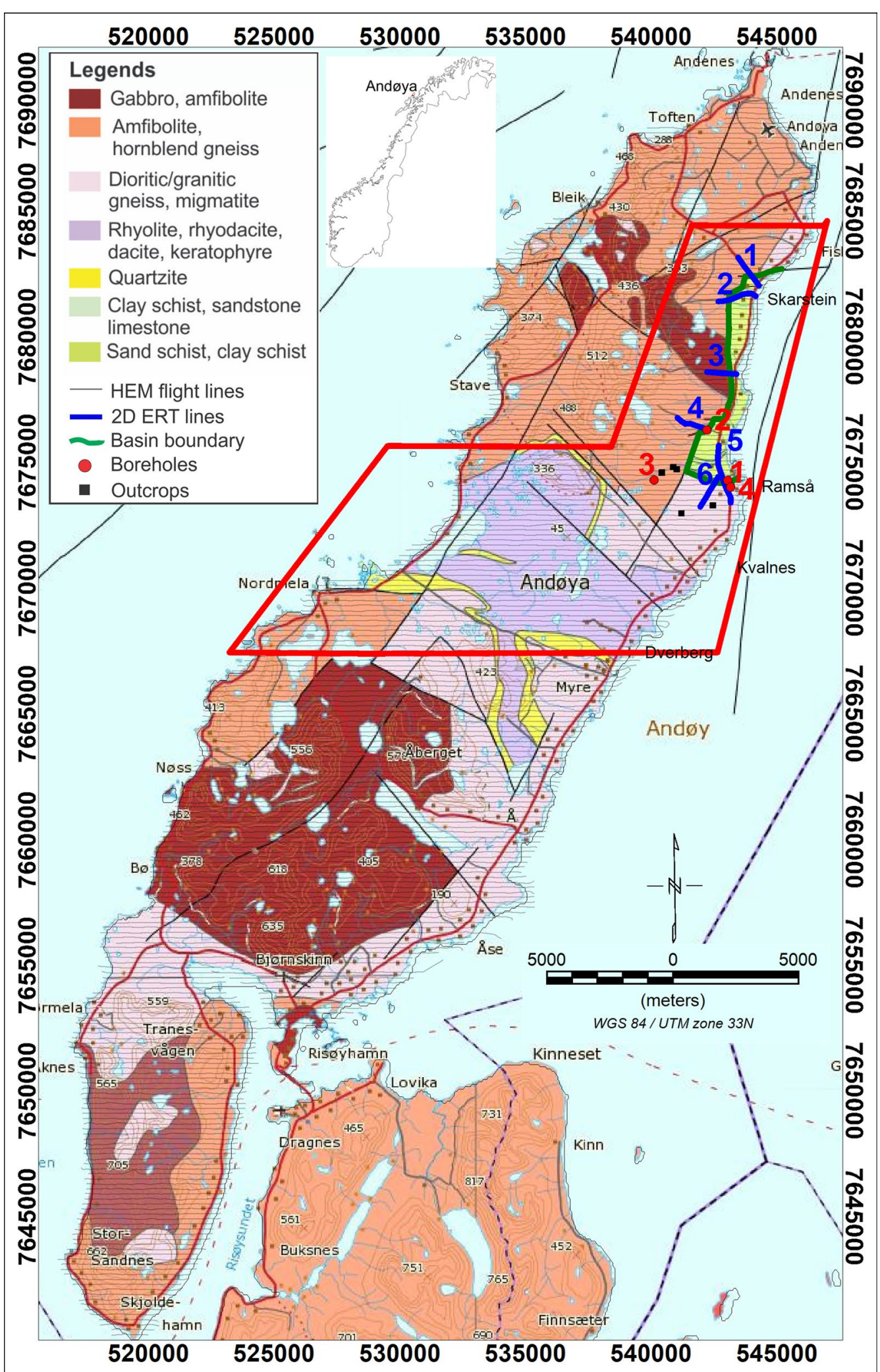

Fig. 1 Bedrock map of Andøya (Henningsen and Tveten 1998) and location of geophysical surveys. Presently assumed western extent of Ramså Basin boundary is shown by green line. Location of various geophysical surveys and basement outcrops (see legends) are also marked. Red polygon shows a part of the HEM data chosen for quasi-3D inversion 
shown by red circles (Fig. 1). The black squares show selected locations of the observed outcropping basement (Fig. 1).

\section{Processing of HEM data}

In the beginning of the airborne survey, the HEM system was calibrated following the standard procedure adapted at Geological Survey of Norway (NGU) for phasing using a ferrite bar and for gain using a calibration coil as recommended by the manufacturer (Geotech 1997). The calibration process set the correct sign and gain to the system with the help of known signal and ensuring that the correct values of in-phase (real part) and quadrature (imaginary part) components were recorded by the HEM system. The calibration was also tested by flying over the seawater and calculating the seawater resistivity.

The HEM data were processed using the HEM module of the Geosoft, Oasis Montaj software (Geosoft 2005) and details of the data processing were reported by Rodionov et al. (2012). In-phase and quadrature data were non-linearly filtered for three fiducials and low-pass filtered for 20 fiducials to suppress high-frequency components from instrumental and the cultural noise. The bird was raised to an altitude of approximately $400 \mathrm{~m}$ above the topographic surface to obtain a background zero level of the system avoiding any electromagnetic responses in the measurements from the ground in order to correct drift in the HEM measurements. The background levels were recorded at 20-30 min intervals and instrumental drift of the system was removed from the data by resetting these points to the initial zero level of the system assuming the drift to be linear (Valleau 2000). Later, residual instrumental and non-linear drifts were manually removed on a line-to-line basis after splitting the data into the flight lines.

After leveling of the HEM data, apparent resistivity was calculated using in-phase and quadrature data together, assuming a homogeneous half-space model of the Earth (Valleau 2000; Whitehead 2005) for five frequencies separately. The sensor height was used in the calculation of the apparent resistivity; therefore, gridded apparent resistivity images were subsequently used to look for some along-line errors in the leveled EM data and to re-level them accordingly as needed. Apparent resistivity image at $6.6 \mathrm{kHz}$ (from coplanar coils) for the whole survey area is shown in Fig. 2. Half-space inversion is a very quick and easy approach to locate the electrically conductive material, but it cannot reveal correct resistivity and depth of the anomalous regions. It is helpful in a qualitative interpretation of the HEM data, but inadequate for a quantitative interpretation.

\section{Quasi-3D inversion of HEM data}

A smaller area (shown by red polygon in Fig. 1 and black polygon in Fig. 2) that covered the sedimentary basin and conductive areas (south of the basin) was inverted using quasi-3D inversion. Quasi-3D inversion is a spatially constrained inversion (SCI) approach developed by the Hydrogeophysics group at the University of Aarhus, Denmark (Viezzoli et al. 2008; AarhusInv 2013). The forward response is computed in $1 D$ in the $\mathrm{z}$-direction and layers in the $x$ - and $y$-directions are related to each other by spatial constraints. Conductivity/resistivity of each layer is iteratively optimized till a good fitting between the observed and the computed data is reached or other stopping criteria of the inversion are satisfied. There could be errors in altitude measurements due to the canopy effects and rapid ascending and descending of the helicopter. Therefore, the altitude of the sensor is also inverted during initial iterations (e.g., five). The inverted altitude is used in the subsequent iterations of the inversion.

Laterally constrained inversion (LCI) is a quasi2D inversion with similar settings as SCI (Auken and Christiansen 2004). First, few flight lines were inverted individually using LCI for all five frequencies with 10,100 and $1000 \Omega \mathrm{m}$ starting models. This was done to get appropriate inversion parameters, e.g., noise floor, lateral and vertical constraints to be used in SCI. Although the LCI results are not shown here, it was observed that the coaxial data (at 980 and $7001 \mathrm{~Hz}$ ) did not fit well and showed a higher mismatch than the coplanar data (at 880, 6606 and 34,133 Hz). The LCI inversion with higher resistivity starting model produced many artifacts and recovered higher resistivity of the seawater in comparison to the starting model with $10 \Omega \mathrm{m}$. Therefore, a starting model consisting of four different resistivities (1) $1 \Omega \mathrm{m}$ for regions near coastline; (2) $10 \Omega \mathrm{m}$ for regions near the Ramså Basin and the conductive zone in the south; (3) $1000 \Omega \mathrm{m}$ for regions near the resistive basement and (4) $100 \Omega \mathrm{m}$ for rest of the region was constructed to perform SCI of coplanar data at three frequencies. The starting model for SCI is shown at the bottom right in Fig. 2. HEM data were recalculated at approximately $30-\mathrm{m}$ spacing using running average of $10 \mathrm{HEM}$ data points. Lateral and vertical constraint values of 1.5 and 2, respectively, were used in the SCI. Root mean square (RMS) misfit between observed and computed data should be 1 for a good data fitting. The RMS misfit varied between 0.5 and 2 for whole SCI of HEM data assuming a 10\% standard noise in the observed data. 


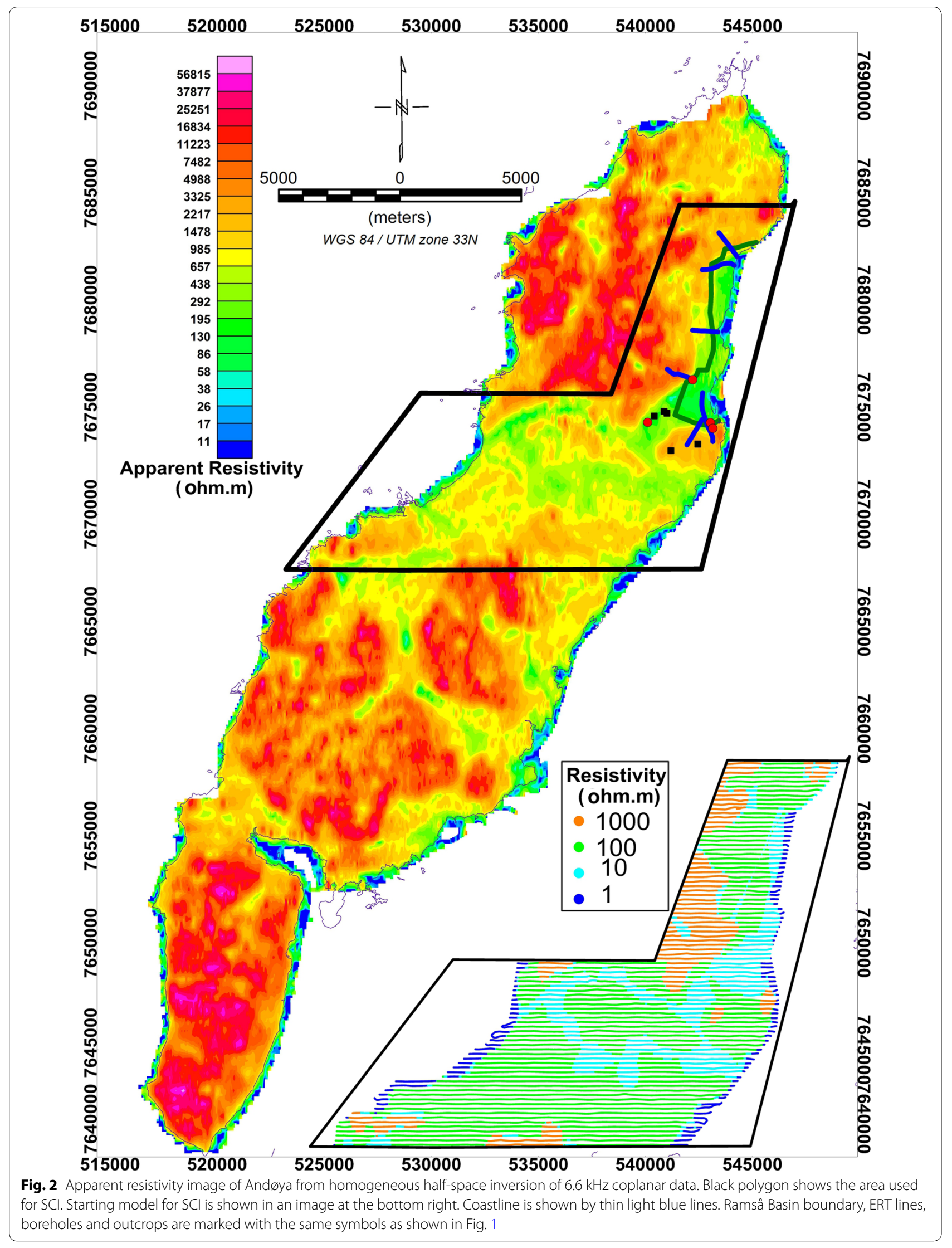




\section{D ERT survey}

\section{Data acquisition and inversion}

ERT data were acquired by NGU along six profiles as shown by the blue lines in Figs. 1 and 2. The electric current and potential difference were measured with Lund system (Dahlin 1993) at 10-m electrode spacing using an ABEM Terrameter LS (ABEM 1999) in a multigradient array configuration. Only ERT line 3 passed along one of the HEM lines (Fig. 1).

ERT data were inverted using the RES2DINV code from Geotomo software (Loke 2007). Standard inversion of least square (L2 norm) and robust inversion (L1 norm) were used to invert 2D ERT data. Inversion results using different norms did not yield any significant change in the main features of the resistivity images. Details of the ERT survey and interpretation of all the ERT lines are described by Brönner et al. (2012).

\section{Borehole logging}

All the boreholes were drilled either in the vicinity of the HEM lines or were located directly below the HEM lines (Fig. 1). Borehole 2 was drilled at the east end of ERT line 4 and the west boundary of the Ramså Basin. Boreholes 1 and 4 were drilled over ERT line 5 . Borehole 1 was located on the south boundary of the basin. Boreholes 3 and 4 were drilled outside of the basin. Logging of several geophysical parameters was done by NGU. Details of the drilling, logging parameters and logging interpretation are discussed by Elvebakk et al. (2016).

\section{Results}

In this section, resistivity model obtained from quasi-3D inversion of coplanar data at three frequencies (880, 6606 and $34,133 \mathrm{~Hz}$ ) using SCI is discussed together with its correlation with resistivity model obtained from borehole logging and 2D ERT. First, we compare the resistivity values obtained from HEM, borehole and ERT. Later, $3 \mathrm{D}$ resistivity image and their detailed interpretation are presented.

\section{Comparison of HEM resistivity with 2D ERT and borehole resistivity}

Generally, ERT and EM methods do not recover the same conductivity of the subsurface especially in the sedimentary basin due to anisotropy where vertical conductivity can be ca. three times greater than horizontal conductivity due to different current flow paths in the two methods (Edwards et al. 1984). Rather than comparing resistivity values one-to-one, we will compare resistivity distribution obtained using two different methods to show a broad correlation between ERT and HEM resistivities.

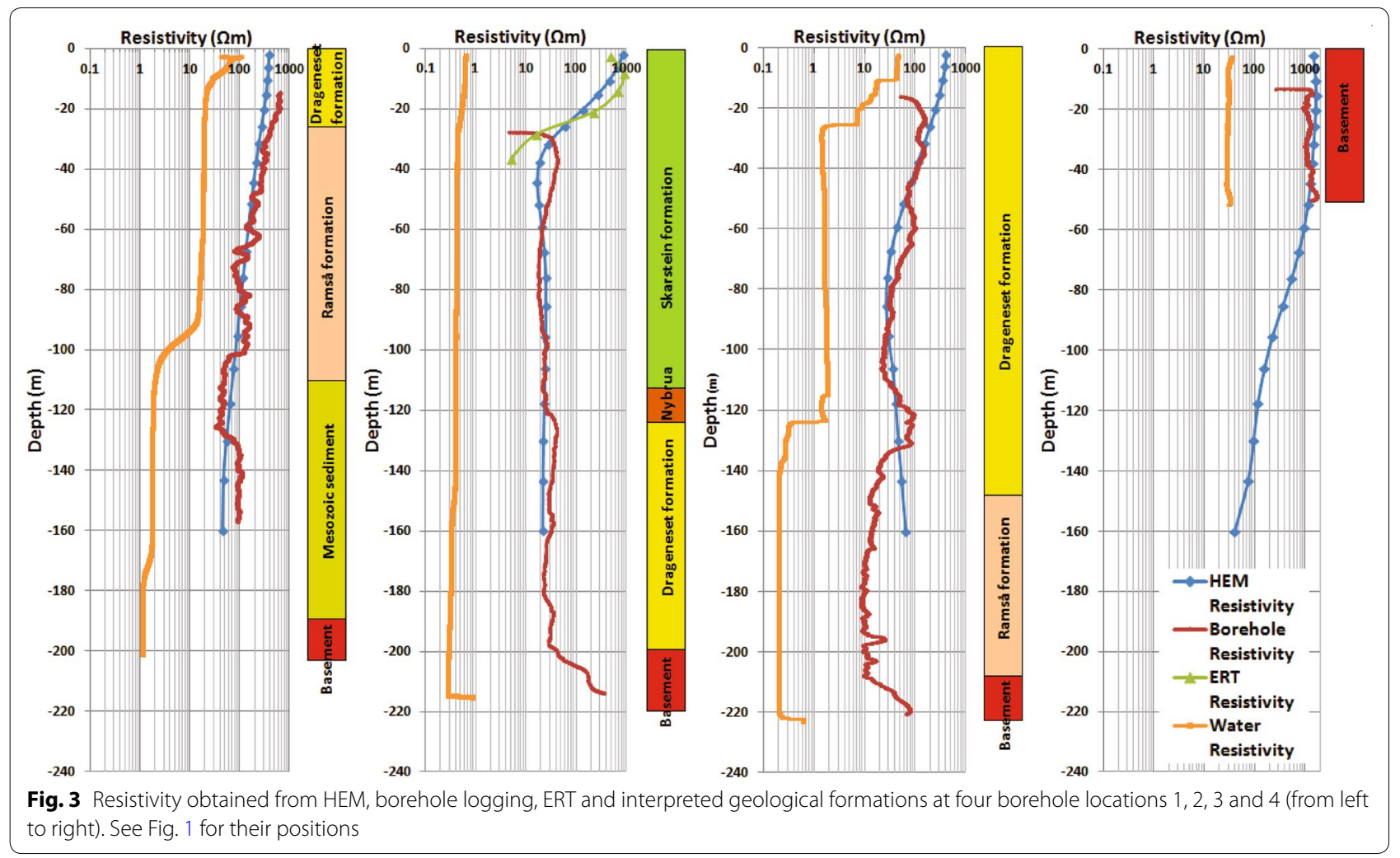


We extracted HEM resistivity from quasi-3D inversion at four borehole locations and compared it with ERT and borehole resistivity data (see Fig. 3). A geological formation-log is also shown in the figure for each borehole. All the formations except the basement belong to the sedimentary basin. ERT data were available only over borehole 2 (boreholes 1 and 4 were ca. $250 \mathrm{~m}$ far from ERT line 5). A good correlation is observed between HEM, ERT and borehole resistivity at all the four borehole locations with a varying range of resistivity between ca. $10 \Omega \mathrm{m}$ and $2000 \Omega \mathrm{m}$. Borehole resistivity of the sedimentary basin varies between 10 and $600 \Omega \mathrm{m}$ at depths. It becomes less than $300 \Omega \mathrm{m}$ below $30 \mathrm{~m}$ depth. Electrical conductivity of the water in the boreholes was also measured and shown in Fig. 3. Formation resistivity correlates well with the corresponding water resistivity in the borehole. Water resistivity measured in the boreholes 1 to 3 is found close to seawater resistivity. The water resistivity of ca. $0.3 \Omega \mathrm{m}$ is observed from boreholes 2 and 3 and it is assumed to represent fossil seawater (Brönner et al. 2017). Borehole resistivity logs and core samples from boreholes 1 to 3 indicate that the basement is reached at a depth of ca. $200 \mathrm{~m}$. Fresh basement is observed in the boreholes 1 and 2, but basement in borehole 3 is weathered and highly compacted (Børre Davidsen NGU, pers. comm. 2017). The borehole resistivity in boreholes 2 and 3 significantly increases when the basement is reached, nevertheless it is less than $100 \Omega \mathrm{m}$ at the boundary of the basement. The borehole resistivity varies between 100 and $500 \Omega \mathrm{m}$ within the basement rock most likely due to the presence of conductive pore water in fractured and weathered bedrock. Borehole 2 does not show significant weathering in the bedrock. The resistivity range of $100-500 \Omega \mathrm{m}$ is also depicted by the sedimentary basin at the surface where it is likely to be saturated with fresh pore water as seen in boreholes 1 and 3. Borehole 4 is drilled into basement only and confirmed that this location is outside the Ramsa Mesozoic basin.

The ERT line 3 (see Fig. 1 for position) was located directly under a HEM flight line. The resistivity crosssections along line 3 from 2D inversion of ERT data (Brönner et al. 2012) and quasi-3D inversion of HEM data are shown in Fig. 4. These cross-sections are plotted in a different color scale from the resistivity image of Fig. 2 to enforce smaller changes. We see similar resistivity ranges along line 3 from both ERT and HEM data, but ERT resistivity is more detailed. The western boundary of the Ramså Basin according to geological map is near 543,100 on the ERT profile (Henningsen and Tveten 1998) whilst both ERT and HEM inversion indicate higher resistivity further west at ca. 542,850. Plots between observed HEM data (symbols) and computed data (solid lines) from quasi-3D inversion (Fig. 5) indicate a good fitting for in-phase data, but not as good for the quadrature data. RMS fit for this line was 1.5 .

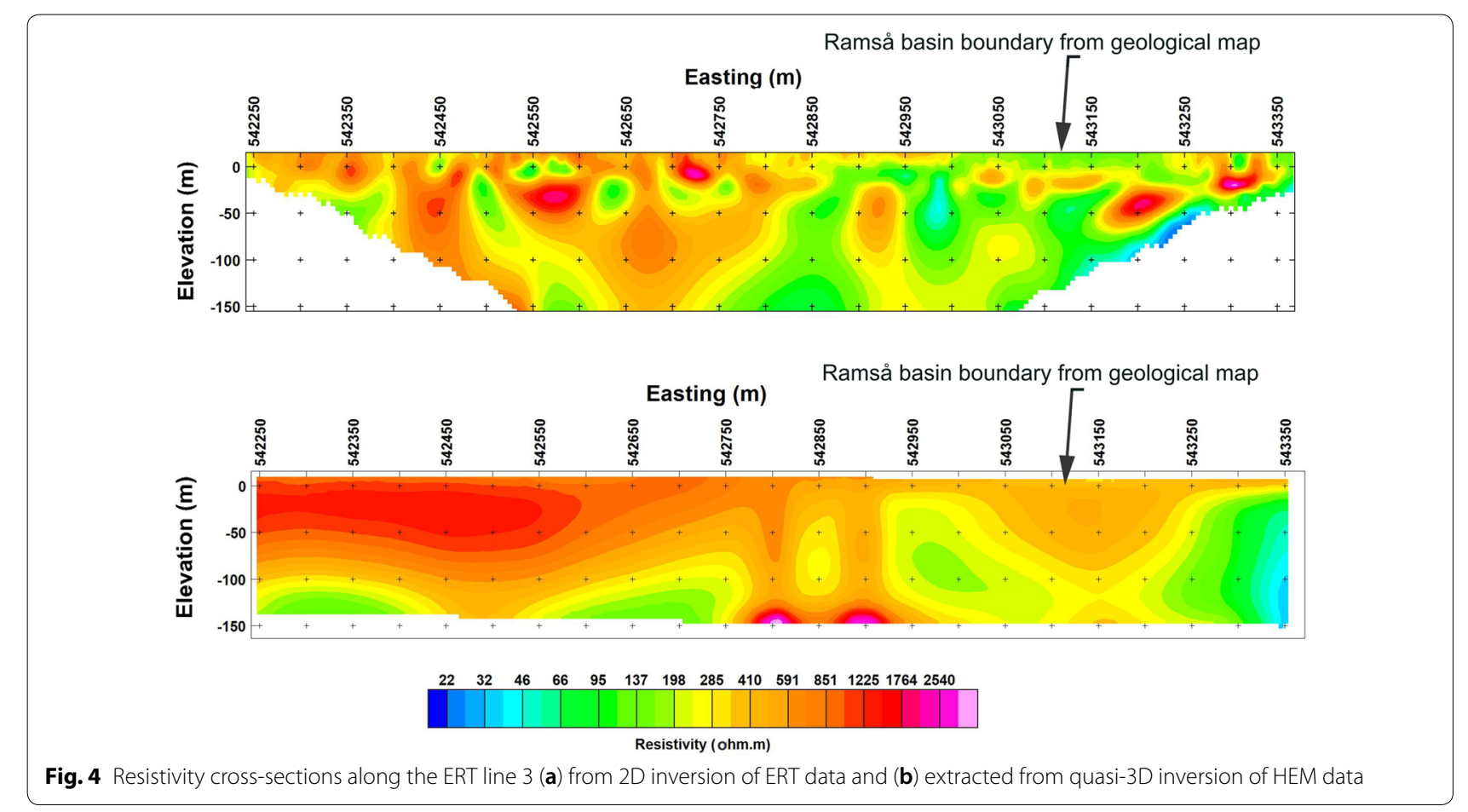



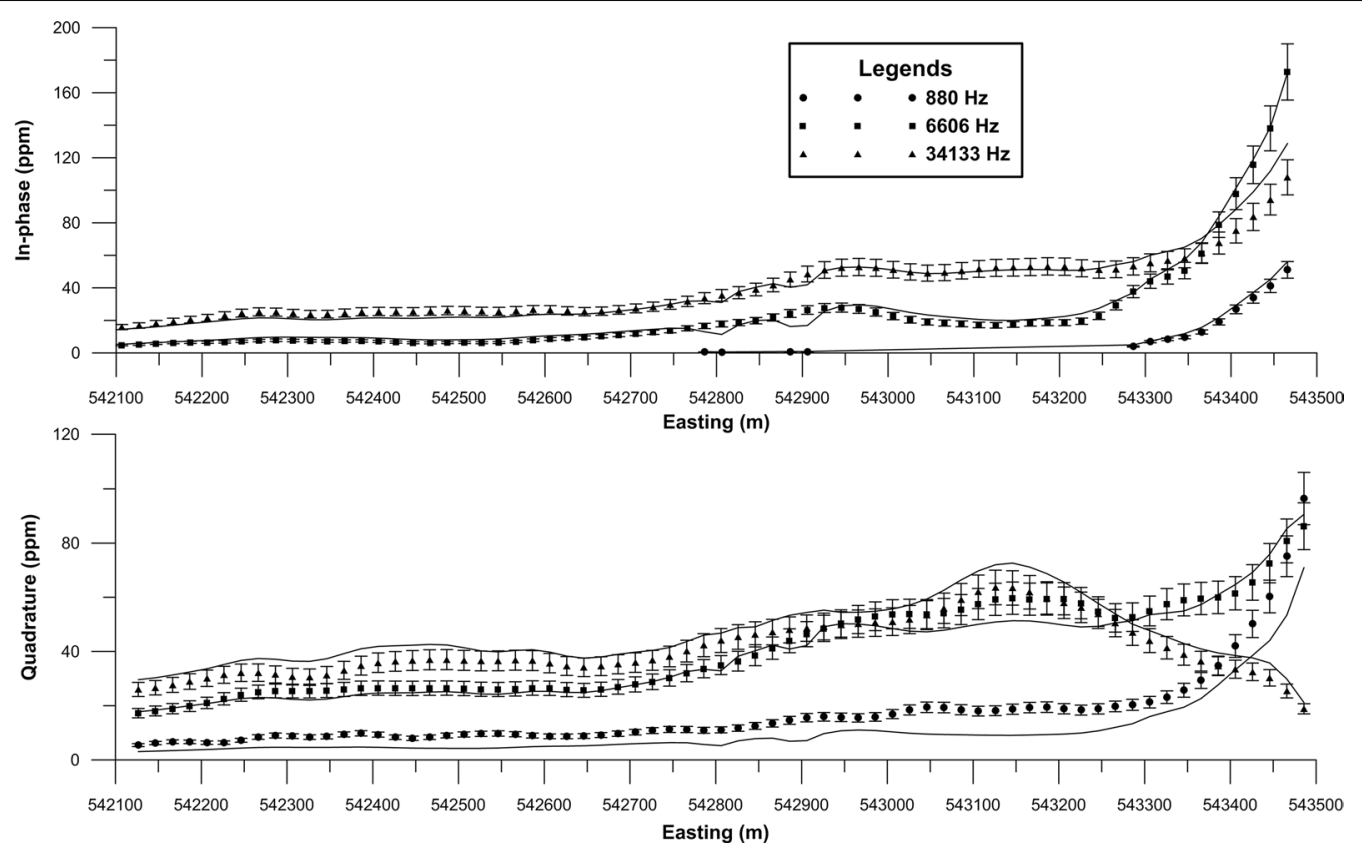

Fig. 5 Fitting between observed HEM data (symbols with error bars) and computed data (solid lines) from quasi-3D inversion along ERT line 3

\section{D HEM resistivity images}

Horizontal HEM resistivity slices interpolated from SCI resistivity model (Geosoft 2012) are shown at various depths in Fig. 6. The Ramsa Basin in the top two slices (at 2 and $20 \mathrm{~m}$ depth) is relatively resistive (500-600 $\Omega \mathrm{m}$ ) compared to the resistivity of the basin at greater depths $(<300 \Omega \mathrm{m})$. High conductive areas are observed in the southern part of the area (marked by $\mathrm{C} 1$ and $C 2$ ), and they become more conductive at greater depths. Outcropping graphite and sulfide minerals were observed at C1 (Børre Davidsen, pers. comm. 2017) which is situated in a high elevated area (ca. $100 \mathrm{~m}$ above m.s.l.). However, the conductive area $\mathrm{C} 2$ is situated in a relatively flat terrain which can contain low resistive saline water. The basin is more conductive at depth and it could be filled with conductive saline water. Figure 6 shows changes in resistivity near the basin boundary in the slices, which indicate that the basin boundary changes at depths. Resistivity variation within basement area reflects significant fracturing of the basement, which is also confirmed by well resistivity logging and core samples.

Figure 7a shows a resistivity section along one of the HEM lines where boreholes 1 and 3 are located. This resistivity cross-section also indicates that the rocks are highly fractured. Small conductive zones at the bottom of the image at ca. 532,750 and 539,000 locations could be artifacts, because they appear only at the bottom of the image and correspond to small HEM responses. However, conductive zones at ca. 534,000, 537,000 and near boreholes 3 and 1 are interpreted to be real features (see Fig. 3 for borehole resistivity), because they correspond to large HEM responses. One of the conductive zones at 537,500 location is confirmed containing outcropping graphite and sulfide minerals. Water from boreholes 3 and 1 was found to be very conductive. The Ramså Basin is not interpreted to be stretching till borehole location 3 in the present geological map (Fig. 1). Figure 7b shows a fit between the observed HEM data (symbols) and the computed data (solid lines) from quasi-3D inversion along this flight line with RMS fit 0.8 .

\section{HEM resistivity interpretation from resistivity slice at $76 \mathrm{~m}$ depth}

A HEM resistivity slice at $76 \mathrm{~m}$ depth is shown in Fig. 8 . We focus on detailed interpretation of this image to check the boundary of the Ramså Basin at this depth. The resistivity image is plotted with a new color scale to adapt the full resistivity range of the grid. HEM, borehole logging and ERT profiles in the area show resistivity range of ca. 10-300 $\Omega \mathrm{m}$ for the Ramså Basin below ca. $30 \mathrm{~m}$ depth. Therefore, contour lines of 100 and $300 \Omega \mathrm{m}$ are plotted in Fig. 8 with thin black lines to identify the boundary of the Ramså Basin. The contoured regions show weathered rocks, mineral zones, and the sedimentary basin altogether. Basement outcrops observed near the location of borehole 3 are either outside or at the $300 \Omega \mathrm{m}$ contour at this depth. A discontinuity of $100-300 \Omega \mathrm{m}$ resistivities around the outcrop is observed in this image. 


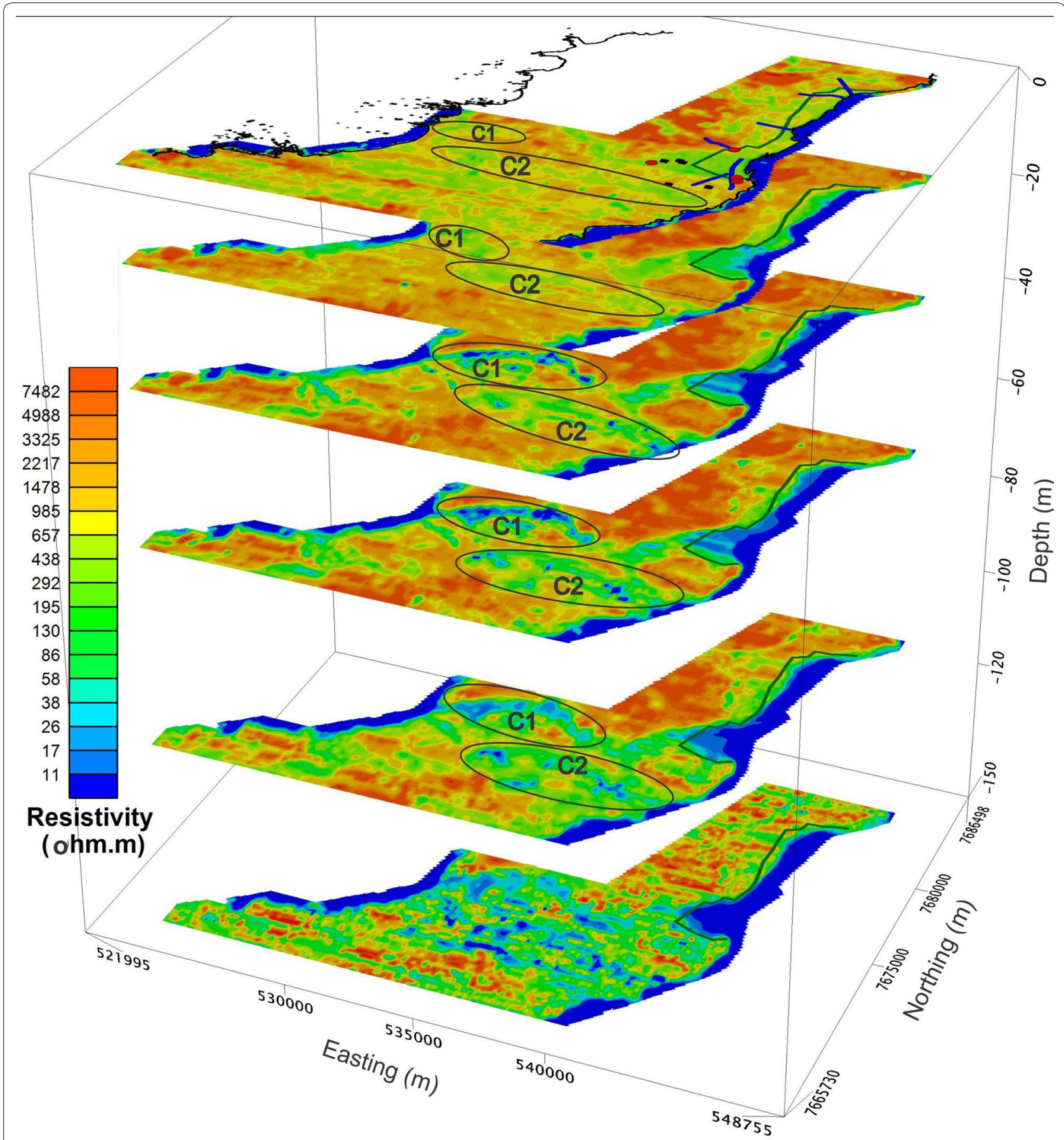

Fig. 6 HEM resistivity slices at 2, 20, 45, 76, 118 and 160 m depth below the surface. Coastlines are shown by black lines. Ramså Basin boundary, ERT lines, boreholes and outcrops are marked with same symbols as shown in Fig. 1. Two conductive zones in southern part are marked by C1 and C2

High-resistivity area of greater than $1000 \Omega \mathrm{m}$ (yellow to red color around borehole 4 in Fig. 8 ) is confirmed as a part of the basement rock by outcrop observations and borehole core samples. This part of the basement rock is interpreted to be fractured at depth because relatively conductive areas of less than $100 \Omega \mathrm{m}$ (green to blue color regions) show up at depth (Fig. 6). Figure 6 depicts a relatively high resistivity near the surface, and lower resistivity started to appear after $20-30 \mathrm{~m}$ depth. Two high conductive areas ( $C 1$ and $C 2)$ having resistivity less than $10 \Omega \mathrm{m}$ are marked in Fig. 8 as well. $C 1$ is confirmed containing graphite and sulfide minerals and several sulfide 

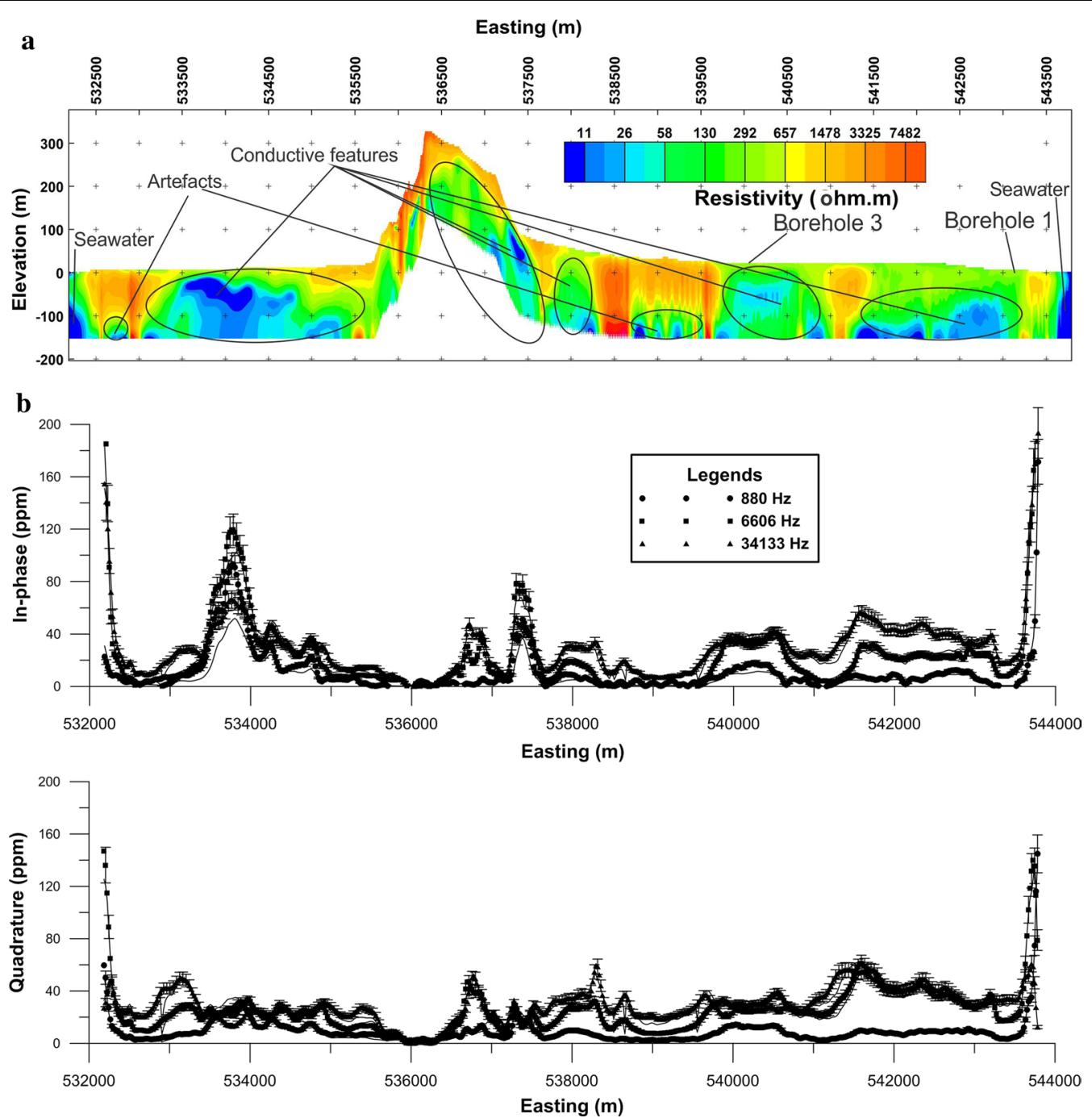

Fig. 7 a HEM resistivity section along a HEM line passing through boreholes 1 and 3. b Fitting between observed HEM data (symbols with error bars) and computed data (solid lines) from quasi-3D inversion. See Fig. 1 for location

and graphite bearing units are observed at many places throughout the area (Børre Davidsen, NGU, pers. comm. 2017). This can be the cause of the observed low resistivity. However, small pockets of blue and green regions can be interpreted either as fractured rock containing saline water or conductive minerals or a combination of both.

\section{Discussion}

The three resistivity methods used here (HEM, ground ERT and borehole logging) vary in their resolving power of electrical resistivity structures at depths. Borehole logging gives a very local variation of the resistivity and has a resolution of few centimeters. ERT data were collected at 10-m electrode spacing and resistivity structures obtained from the inversion of ERT data would have ca. $10 \mathrm{~m}$ or less resolution. HEM data was measured by EM coils at ca. $50 \mathrm{~m}$ height above ground and then inverted with data spacing of $30 \mathrm{~m}$ (running average of 10 HEM data points) along the line and $200 \mathrm{~m}$ across the flight lines. The HEM interpretation results in a spatial resolution of ca. $70 \mathrm{~m}$ depending on sensor height and average speed of flying (Smith et al. 2011). The spatially constrained inversion of HEM data produces a rather smooth image of the subsurface resistivity in comparison to 2D ERT data. With all these constraints, similar resistivity values at four borehole locations shown by the HEM, ERT and borehole logging (Fig. 3) establish the validity of the HEM inversion results.

A sedimentary basin may have resistivity a few tens to thousands $\Omega \mathrm{m}$ depending on the porosity, saturation and 


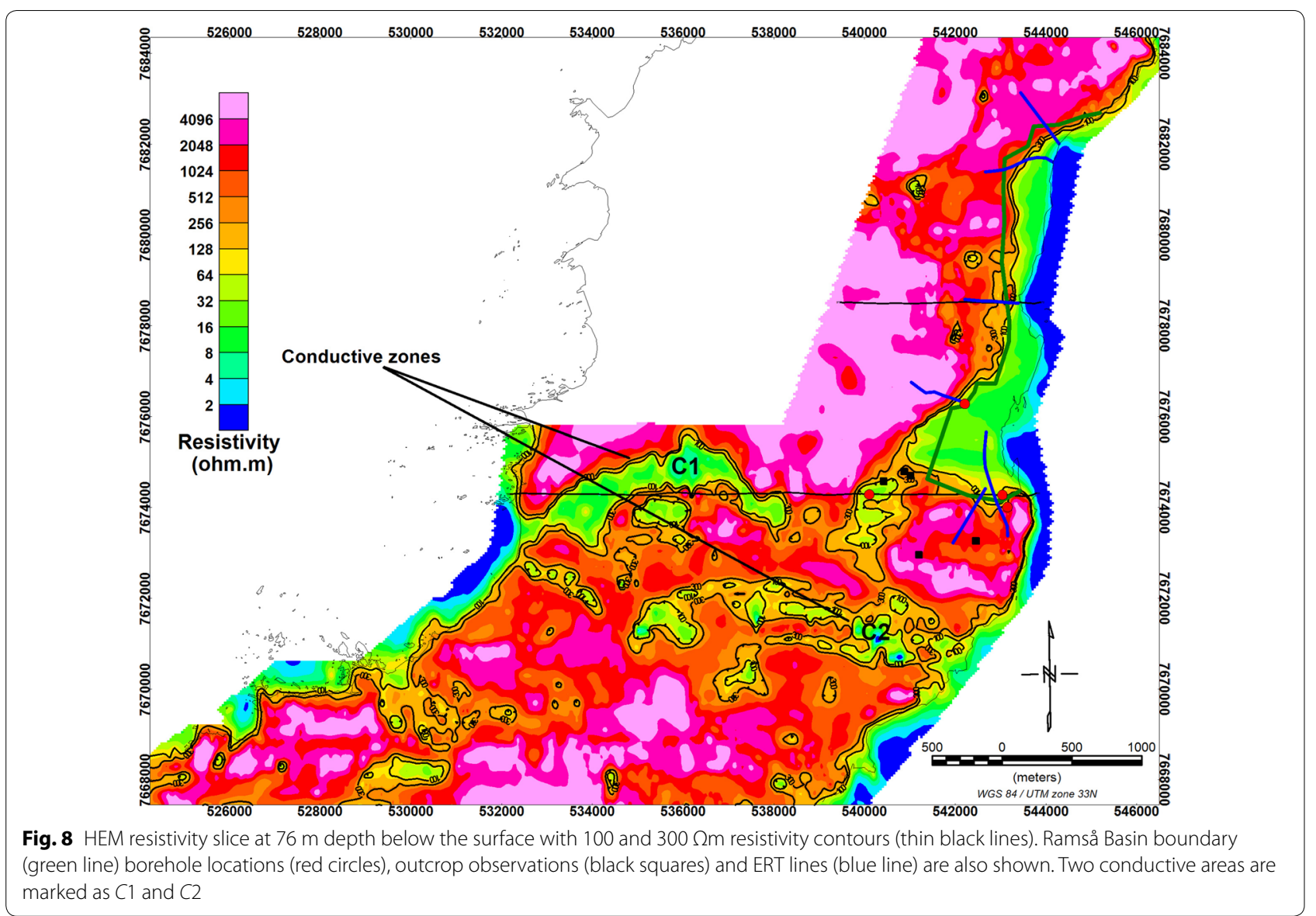

the fluid conductivity (Dobrin 1960). In general, there should be a clear contrast between the resistivity of the basement rock (few thousands $\Omega \mathrm{m}$ ) and the sedimentary rocks (few tens to few hundreds $\Omega \mathrm{m}$ ). However, basement rock can show a similar range of resistivity as sedimentary rocks if the basement is fractured and filled with conductive pore water. This is observed at the bottom of borehole 2 when the basement is reached (Fig. 3). Similar resistivity for sedimentary rocks can also be attributed to the weathered basement as observed at the bottom of borehole 3 (Fig. 3). Conductive minerals like graphite and sulfide have resistivity as low as $1 \Omega \mathrm{m}$ (Dobrin 1960) in the same range of saline water resistivity. Consequently, resistivity and EM methods alone cannot differentiate such geological domains. Additional information about the area from other geophysical or geological observations is necessary to make an accurate interpretation in such cases.

Water conductivity varied with depth in four boreholes in the area and showed a direct correlation with formation resistivity obtained by the borehole logging. HEM resistivity at these locations correlated well with the borehole resistivity for a range of $10-2000 \Omega \mathrm{m}$. A resistivity range of $10-600 \Omega \mathrm{m}$ is attributed to the Ramså Basin according to the borehole observations.

The previously assumed boundary of Ramså Basin was mainly based on geological observations and shallow drillings. Until recently, only a few geophysical datasets were available. The latest HEM, ERT, airborne magnetic and gravity as well as 2D seismic surveys (Baranwal et al. 2017; Brönner et al. 2017) have allowed us to re-explore the area and to redraw the Ramsa Basin boundary. Borehole location 3 was considered outside the sedimentary basin according to the earlier geological interpretation, but recent geophysical interpretations from airborne gravity and magnetic survey (Brönner et al. 2017) suggest that the basin extends to this location. This is confirmed by the core samples obtained from borehole 3 . Interpretation of HEM inversion results also suggests similar extent of the Ramså Basin.

Half-space inversion of HEM data yields apparent resistivity and locates conductors, but fails to estimate correct depth and resistivity. Still, it shows conductive saline water-saturated sedimentary rocks and exposed basement rock quite well and helps to clarify the extent of the Ramså Basin. The lateral and vertical extent of the 
Ramså Basin estimated by Brönner et al. (2012) from ERT lines 1 and 2 (Fig. 1) matches well with the interpretation from HEM half-space inverted model (Fig. 2) and spatially constrained inversion model (green colored zone with $50-500 \Omega m$ resistivity in Fig. 6).

The apparent resistivity image shows the basin boundary at ca. $700 \mathrm{~m}$ on ERT line 3 from its west end (Fig. 2). The western boundary of the Ramsa Basin as observed from the geological map (Henningsen and Tveten 1998) is supposed to be at ca. $930 \mathrm{~m}$ on the ERT line 3 (Fig. 4) from its west end. However, resistivity cross-sections from ERT line 3 and HEM along the same line (Figs. 4a, b) suggest a resistive boundary of $300-500 \Omega \mathrm{m}$ at ca. $600 \mathrm{~m}$ location, i.e., ca. $300 \mathrm{~m}$ to the west. This could be the actual western boundary of the Ramså Basin. Brönner et al. (2017) also observed a similar extent of the Ramså Basin from airborne gravity and magnetic data. Furthermore, the shallow part of the basement seems weathered or fractured from 0 to $600 \mathrm{~m}$ along this line (Figs. 4a, b), because the resistivity is not as high, up to a few thousands $\Omega \mathrm{m}$, as it should be for a fresh basement rock (Elvebakk 2011). A rather higher contrast of resistivity from HEM interpretation exists at the beginning of the ERT line 3 where bedrock could be fresher, without fracturing and weathering (Fig. 4b).

ERT lines 4 and 5 (Fig. 1) had shown that high resistive basement extends along part of these profiles (Brönner et al. 2012), which is in very good agreement with the high-resistivity areas shown on HEM apparent resistivity image (red zones along ERT lines 4 and 5 in Fig. 2). Spatially constrained inversion of HEM data recovered similar lateral extent and depth estimation of the basement along these ERT lines, although more fractured at ca. $160 \mathrm{~m}$ depth (Fig. 6).

Core samples from borehole 1, 2 and 3 confirm that basement is at ca. $200 \mathrm{~m}$ depth at these locations (Fig. 3). HEM data could not be interpreted deeper than $160 \mathrm{~m}$ due to limited skin depth of the applied EM frequencies. Fresh and weathered basements are observed in borehole locations 2 and 3, respectively, with low resistivity (100-500 $\Omega \mathrm{m})$. Water resistivity from boreholes 1 to 3 confirmed the presence of saline water in deeper parts of the boreholes. Highly conductive water (ca. $0.3 \Omega \mathrm{m}$ ) was reported from different depths at borehole locations 2 and 3, and it is assumed to be fossil seawater trapped in troughs. We observe further low resistive areas in the Ramså Basin from HEM interpretation that could be due to the presence of saline water.

We note that a few of the basement outcrops are observed near borehole location 3 (Fig. 1). Magnetic and gravity data interpreted this part of basement outcrops to be a horst structure (Brönner et al. 2017). SCI of HEM data show $300-600 \Omega \mathrm{m}$ resistivity down to $20 \mathrm{~m}$ depth and $<300 \Omega \mathrm{m}$ below it (Fig. 6) in this region. Resistivitybased geophysical methods lead to an interpretation of the outcrop locations (black rectangles) either to be a part of the basin or bedrock filled with conductive pore water or weathered bedrock instead of fresh bedrock due to its low resistivity. Borehole location 3 and outcrop observations near borehole 3 could be separated by ca. $500 \Omega \mathrm{m}$ resistivity boundary at the surface. When basement continues to a greater depth, it shows a low resistivity of ca. $200 \Omega \mathrm{m}$ down to $160 \mathrm{~m}$ depth (Fig. 6). We observed a discontinuity of $100-300 \Omega \mathrm{m}$ resistivity around the outcrops near borehole 3 ; however, the rest of the basin depicted a resistivity $<100 \Omega \mathrm{m}$ at $76 \mathrm{~m}$ depth (Fig. 8). The $100 \Omega \mathrm{m}$ contour lines (Fig. 8) could separate the extended basin in two parts at basement outcrop observations to match with other geophysical and outcrop observations. Therefore, ca. $100 \Omega \mathrm{m}$ resistivity seems to be appropriate for this part of the Ramså Basin at $76 \mathrm{~m}$ depth. The low resistivity observed at outcrop locations could be due to fractured or weathered basement filled with water or conductive materials. The lateral extent of the sedimentary basin beyond the borehole 3 location should be confirmed by additional borehole and geological observations.

\section{Conclusion}

Helicopter EM survey is a fast and economical tool to explore subsurface electrical resistivity of a large area. Half-space inversion of HEM data can locate conductors, but may fail to estimate their depth. 3D inversion of HEM data estimates the depth and resistivity of the subsurface. Resistivity obtained from quasi-3D inversion of HEM data establishes its validity and usefulness by showing good correlation with borehole logging and ground ERT. HEM inversion presents a continuous 3D subsurface resistivity image of a larger area in comparison to what could have been obtained from few ERT lines and borehole logging. The Ramså sedimentary basin shows a rather wide range of resistivity between ca. 10 and $600 \Omega \mathrm{m}$ at depths. EM and other resistivity methods alone cannot distinguish between fractured and weathered basement or basin sediments with similar resistivity ranges.

The basement in boreholes 2 and 3 shows a significantly lower resistivity due to the presence of very conductive pore water and weathered basement. The conductivity of water in pores or fractures plays a significant role in the formation resistivity of the sedimentary basin and the basement rock in Andøya.

The HEM interpretation in agreement with other geophysical data indicates an extension of the Ramså Basin beyond its earlier mapped boundary. However, an extension of the Ramsa Basin west of borehole location 3 
shown by HEM interpretation needs to be confirmed by drilling and other geophysical methods.

Highly conductive zones are newly identified by HEM data interpretation where one of the areas is characterized by outcropping graphite and sulfide minerals. Other areas showing similar range of high conductivity except the coastal regions with saline water may also contain conductive minerals, but they need to be further investigated with ground truth and drilling.

\begin{abstract}
Abbreviations
1D: One dimensional; 2D: Two dimensional; 3D: Three dimensional; AEM: Airborne EM; DC: Direct current; EM: Electromagnetic; ERT: Electrical resistivity tomography; HEM: Helicopter-borne frequency-domain EM; LCl: Laterally constrained inversion; NGU: Geological Survey of Norway; RMS: Root mean square; SCl: Spatially constrained inversion.
\end{abstract}

\section{Acknowledgements}

We sincerely thank two anonymous reviewers for their constructive and insightful comments and suggestions in improving the quality of the manuscript. We are very thankful to our colleagues from NGU for geophysical data acquisition and its processing. We acknowledge Børre Davidsen from NGU for performing the geological interpretation of borehole cores and field observations. HEM interpretation was performed under Ramså Basin project (RABIS) funded by Wintershall, Mærsk Oil, Equinor, Lundin, AkerBP and the Norwegian Petroleum Directorate. Norwegian Public Roads Administration is acknowledged for financing the borehole loggings.

\section{Authors' contributions}

VCB has written the manuscript and interpreted the HEM data including the quasi-3D (SCl) inversion. MB was leader of the Ramså Basin project. MB and JSR helped in correlating the interpretation of all the data presented in this paper and other geophysical data. They also discussed preparation of the manuscript. HE had collected and interpreted the borehole data. ED had collected and inverted the ERT data. All authors read and approved the final manuscript.

\section{Funding}

HEM survey was funded under a Norwegian government project called Minerals in North Norway (MINN). Norwegian Public Road administration financially supported logging of the four wells. Overall work was performed under Ramså Basin project.

\section{Availability of data and materials}

The datasets used and/or analyzed during the current study are available from the corresponding author on reasonable request.

\section{Competing interests}

The authors declare that they have no competing interests.

\section{Author details}

${ }^{1}$ Geological Survey of Norway (NGU), Torgarden, Postbox 6315, Trondheim 7491, Norway. ${ }^{2}$ Norwegian University of Science and Technology (NTNU), Trondheim, Norway.

Received: 8 July 2019 Accepted: 15 April 2020

Published online: 28 April 2020

\section{References}

AarhusInv (2013) Manual for inversion program, ver. 6.1, HydroGeophysics Group (HGG), University of Aarhus, Denmark, pp 71. http://www.hgg.geo. au.dk/HGGsoftware/em1dinv/em1dinv_manual.pdf

ABEM (1999) ABEM Terrameter SAS 4000/SAS 1000. Instruction manual. ABEM Printed Matter 93101
Anschütz H, Bazin S, Pfaffhuber AA (2014) AEM method description \& project examples, NGI report 20130058-02-R_ENG, pp 59

Asch TH, Deszcz-Pan M, Burton BL, Ball LB (2008) Geophysical characterization of American River levees, Sacramento, California, using electromagnetics, capacitively coupled resistivity, and dc resistivity, US Geological Survey Open-File Report 2008-1109, pp 12

Auken E, Christiansen AV (2004) Layered and laterally constrained 2D inversion of resistivity data. Geophysics 69:52-761

Auken E, Boesen T, Christiansen AV (2017) A review of airborne electromagnetic methods with focus on geotechnical and hydrological applications from 2007 to 2017. Adv Geophys 58:47-93

Baranwal VC, Dalsegg E, Elvebakk H, Rønning JS, Brönner M (2017) 3D resistivity interpretation of helicopter-borne frequency-domain EM (HEM) data from Ramså Basin and around in Andøya, Norway. In: Extended Abstract, Second European airborne electromagnetics conference, EAGE. http:// doi.org/10.3997/2214-4609.201702169

Brönner M, Dalsegg E, Fabian K, Rønning JS, Tønnesen JF (2012) Geophysical methods. In: Olesen O, Bering D, Brönner M, Dalsegg E, Fabian K, Fredin O, Gellein J, Husteli B, Magnus C, Rønning JS, SolbakkT, Tønnesen JF, $\varnothing$ verland JA (eds) Tropical weathering in Norway, TWIN final report, NGU Report 2012.005:19-26

Brönner M, Johansen TA, Baranwal VC, Črne A, Davidsen B, Elvebakk H, Engvik A, Forthun T, Gellein J, Henningsen T, Lutro O, Margreth A, Midbøe P, Ruud BO, Rueslåtten H, Ryseth A, Rønning JS, Schiellerup H, Schöneberger J, Smelror M, Tveten E (2017) Ramså Basin, Northern Norway: an integrated study, NGU Report, 2017.027, pp 290

Christensen CW, Pfaffhuber AA, Anschutz H, Smaavik TF (2015) Combining airborne electromagnetic and geotechnical data for automated depth to bedrock tracking. J Appl Geophys 119:178-191

Cox LH, Wilson GA, Zhdanov MS (2012) 3D inversion of airborne electromagnetic data. Geophysics 77:WB59-WB69

Dahlin T (1993) On the automation of 2D resistivity surveying for engineering and environmental applications. Ph.D. thesis, Department of Engineering Geology, Lund Institute of Technology, Lund University. ISBN 91-6281032-4, pp 187

Dalland A (1975) The Mesozoic rocks of Andøy, northern Norway. Nor Geol Unders 316:271-287

Dobrin MB (1960) Introduction to geophysical prospecting. McGraw-Hill, New York, p 446

Edwards RN, Nobes DC, Gomez-Trevino E (1984) Offshore electrical exploration of sedimentary basins: the effects of anisotropy in horizontally isotropic, layered media. Geophysics 49(5):566-576

Elvebakk H (2011) Sammenstilling av resistivitet, seismiske hastigheter og naturlig gammastråling i norske bergarter. NGU Rapport 2011(047):60 (in Norwegian)

Elvebakk H, Brønner M, Gellein J, Rønning JS (2016) Geofysisk logging av 4 borehull i Ramså feltet, Andøya. NGU report 2016.023 (in Norwegian)

Friis JP (1903) Andøens kullfelt. Nor Geol Unders 36(1):1-38 (in Norwegian)

Geosoft (2005) Helicopter electromagnetic data processing, analysis and presentation System for Oasis montaj v. 6.2: tutorial and user guide manual. Geosoft Incorporated, Toronto

Geosoft (2012) Oasis montaj How-to-guide: 3D gridding-create voxels using 3D gridding methods. Geosoft Incorporated, Toronto

Geotech (1997) Hummingbird electromagnetic system. User's manual. Geotech Ltd., Toronto

Guillemoteau J, Sailhac P, Behaegel M (2011) Regularization strategy for the layered inversion of airborne TEM data: application on data acquired over the basin of Franceville (Gabon). Geophys Prospect 59:1132-1143

Henningsen T, Tveten E (1998) Berggrunnskart (Bedrock map) AND ØYA, M 1:250 000. Norges geologiske undersøkelse, Trondheim

Høyer AS, Jørgensen F, Foged N, He X, Christiansen AV (2015) Three-dimensional geological modelling of AEM resistivity data- a comparison of three methods. J Appl Geophys 115:65-78

Legault J (2015) Airborne electromagnetic systems — state of the art and future directions. CSEG Rec 40(6):38-49

Ley-Cooper Y, Macnae J, Tweed S (2008) Estimating subsurface porosity and salt loads using airborne geophysical data. Near Surf Geophys 6:31-37

Li WB, Zeng ZF, Li J, Chen X, Wang K, Xia Z (2016) 2.5D forward modeling and inversion of frequency-domain airborne electromagnetic data. Appl Geophys 13:37-47 
Liu Y, Yin C (2016) 3D inversion for multi-pulse airborne transient electromag netic data. Geophysics 81:1-8

Liu Y, Farquharson CG, Yin C, Baranwal VC (2018) Wavelet-based 3-D inversion for frequency-domain airborne EM data. Geophys J Int 213(1):1-15

Loke MH (2007) RES2INV ver. 3.56. Geoelectrical imaging 2D \& 3D. Instruction manual. http://www.geoelectrical.com

Midbøe P (2011) Geologisk introduksjon til Ramsåfeltet, Andøya og Sortlandsundetbassenget Vesterålen, 4 utgave. Rapport Statoil (in Norwegian)

Okazaki K, Mogi T, Utsugi M, Ito Y, Kunishima H, Yamazaki T, Takahashi Y, Hashimoto T, Yamamaya Y, Ito H, Kaieda H, Tsukuda K, Yuuki Y, Jomori A (2011) Airborne electromagnetic and magnetic surveys for long tunnel construction design. Phys Chem Earth 36:1237-1246

Roach IC, Jaireth S, Costelloe MT (2014) Applying regional airborne electromagnetic (AEM) surveying to understand the architecture of sandstonehosted uranium mineral systems in the Callabonna Sub-basin, Lake Frome region, South Australia. Aust J Earth Sci 61:659-688

Rodionov A, Ofstad F, Tassis G (2012) Helicopter-borne magnetic, electromag netic and radiometric geophysical survey at Andøya, Nordland County, NGU Report no 2012.056

Scheunert M, Ullmann A, Afanasjew M, Börner RU, Siemon B, Spitzer K (2016) A cut- $\&$-paste strategy for the 3-D inversion of helicopter-borne electromagnetic data-I. 3-D inversion using the explicit Jacobian and a tensorbased formulation. J Appl Geophys 129:209-221

Siemon B, Christiansen AV, Auken E (2009) A review of helicopter-borne electromagnetic methods for groundwater exploration. Near Surf Geophys 7:629-646
Siemon B, Steuer A, Ullmann A, Vasterling M, Voß W (2011) Application of frequency-domain helicopter-borne electromagnetic for groundwater exploration in urban areas. Phys Chem Earth 36:1373-1385

Smith RS, Rodney K, Hodges G, Lemieux J (2011) A comparison of airborne electromagnetic data with ground resistivity data over the Midwest deposit in the Athabasca basin. Near Surf Geophys 9:319-330

Valleau N (2000) HEM data processing - a practical overview. Explor Geophys 31:584-594

Viezzoli A, Christiansen AV, Auken E, Sørensen K (2008) Quasi-3D modeling of airborne TEM data by spatially constrained inversion. Geophysics 73:F105-F113

Viezzoli A, Munday T, Auken E, Christiansen AV (2010) Accurate quasi-3D versus practical full 3D inversion of AEM data-the Bookpurnong case study. Geography 149:23-31

Vogt JHL (1905) Om Andøens jurafelt, navnlig om landets langsomme nedsynken under juratiden og den senere hævning samt gravforkastning. Nor Geol Unders 43(5):1-67

Whitehead N (2005) Helicopter electromagnetic data processing, analysis and presentation system for Oasis montaj v6.2, Geosoft HEM system tutorial and user guide, pp 54

\section{Publisher's Note}

Springer Nature remains neutral with regard to jurisdictional claims in published maps and institutional affiliations.

\section{Submit your manuscript to a SpringerOpen ${ }^{\circ}$ journal and benefit from:}

- Convenient online submission

$\checkmark$ Rigorous peer review

- Open access: articles freely available online

- High visibility within the field

- Retaining the copyright to your article

Submit your next manuscript at $\boldsymbol{\nabla}$ springeropen.com 